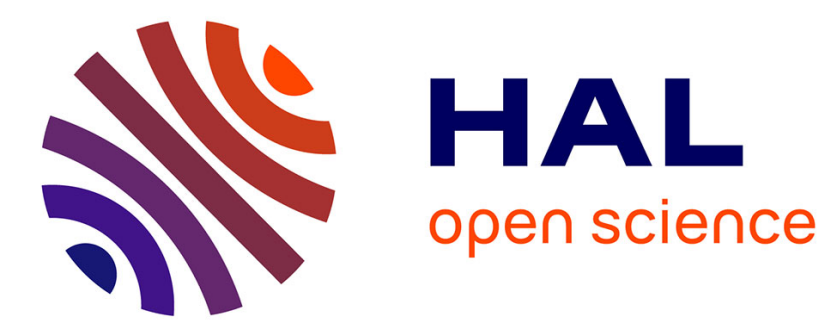

\title{
Intermetallic Texture Analysis by X-Ray, Neutron and Electron Backscattered Diffraction
}

\author{
T. Baudin, M. Dahms, C. Quesne, R. Penelle
}

\section{To cite this version:}

T. Baudin, M. Dahms, C. Quesne, R. Penelle. Intermetallic Texture Analysis by X-Ray, Neutron and Electron Backscattered Diffraction. Journal de Physique IV Proceedings, 1996, 06 (C2), pp.C2-141C2-146. 10.1051/.jp4:1996219 . jpa-00254197

\section{HAL Id: jpa-00254197 https://hal.science/jpa-00254197}

Submitted on 1 Jan 1996

HAL is a multi-disciplinary open access archive for the deposit and dissemination of scientific research documents, whether they are published or not. The documents may come from teaching and research institutions in France or abroad, or from public or private research centers.
L'archive ouverte pluridisciplinaire HAL, est destinée au dépôt et à la diffusion de documents scientifiques de niveau recherche, publiés ou non, émanant des établissements d'enseignement et de recherche français ou étrangers, des laboratoires publics ou privés. 


\title{
Intermetallic Texture Analysis by X-Ray, Neutron and Electron Backscattered Diffraction
}

\author{
T. Baudin, M. Dahms*, C. Quesne and R. Penelle \\ Université de Paris Sud, Laboratoire de Métallurgie Structurale, U.A. C.N.R.S. 1107, Bât. 413, \\ 91405 Orsay cedex, France \\ * Institut für Werkstofforschung, GKSS Forschungszentrum, Max-Planck-Str. 1, 21502 Geesthacht, \\ Germany
}

\begin{abstract}
Texture characterization of intermetallic materials implies to solve the problem of overlapped pole figures of one or several phases when they are carried out by X-ray or neutron diffraction. Moreover, if the harmonic method is used to calculate the texture function, a complementary iterative method must be introduced to define the total texture function. A second iterative method must still be used to solve the problem of incomplete pole figures measured by $\mathrm{X}$-ray diffraction in reflection. An other approach consists in using individual orientation measurements, which allow to estimate the local texture which can be correlated to the microstructure but also to the global one if the orientation number is sufficient.
\end{abstract}

\section{INTRODUCTION}

Yamaguchi and Inui [1] showed that mechanical properties of the titanium aluminide (TiAl) strongly depend of the texture. So, it becomes useful to characterize quantitatively the texture using the Orientation Distribution Function (ODF).

The global (X-ray or neutron) and local (EBSD [2]) texture analyses are compared and discussed enlightening their respective advantages and disadvantages. So, when the ODF is calculated from pole figures measured by X-ray or neutron diffraction, it is necessary to separate the $(002) /(200) \ldots$ overlapped reflections of the tetragonal phase and eventually the overlapping of some $\mathrm{TiAl}$ and $\mathrm{Ti}_{3} \mathrm{Al}$ (hexagonal phase) reflections in the case of $\gamma / \alpha_{2}$ aluminides [3]. On an other hand, to calculate the ODF from individual orientations, it is necessary to know the minimum orientation number to obtain a statistical ODF comparable to that calculated from pole figures.

The global texture analysis assumes the homogeneity of the microstructure because only 3 orientation parameters are measured knowing that a grain in a polycrystal is defined by 6 parameters. The 3 other parameters (or 2 in the case of a two dimensional analysis) correspond to the grain location parameters in the polycrystal that can only be defined from a local technique of orientation measurements.

\section{ODF ANALYSIS}

To calculate the ODF $\mathrm{F}(\mathrm{g})$ which corresponds to the probability to find grains with an orientation $\mathrm{g}$ within $\mathrm{dg}$ in the studied material, the harmonic method $[4,5,6,7,8]$ is used and is described using the Roe formalism. From a global or a local analysis, the next equation must be solved :

$$
\mathrm{F}(\mathrm{g})=\sum_{\mathrm{l}} \sum_{\mathrm{m}} \sum_{\mathrm{n}} \mathrm{f}_{\mathrm{Imn}} \mathrm{T}_{\mathrm{mn}}^{\mathrm{l}}(\mathrm{g})
$$


$\mathrm{F}(\mathrm{g})$ is expressed in the Euler space; $\mathrm{g}$ is an orientation characterized by $\psi, \theta, \varphi$ (Roe notation) or $\varphi_{1}, \phi$, $\varphi_{2}$ (Bunge notation); $\mathrm{T}_{\mathrm{mn}}^{1}$ are spherical harmonic functions and $\mathrm{f}_{\mathrm{lmn}}$ are the ODF coefficients.

\subsection{X-ray or neutron diffraction}

The equation which links the pole densities $q(\eta, \chi)$ (normalized diffracted intensities at a point defined by the $\eta$ and $\chi$ spherical coordinates on the $\{$ hkl $\}$ pole figure) to the ODF must be solved

$$
q(\eta, \chi)=\frac{1}{2 \pi} \int_{0}^{2 \pi} F(g) d \gamma
$$

Where $d y$ is the differential element of a rotation around the normal of the diffracting plane.

The two terms of this equation are thus expanded on the spherical harmonic basis. For the second term of equation (2), one finds equation (1) and for the first term of equation (2), one obtains :

$$
\mathrm{q}(\eta, \chi)=\sum_{1} \sum_{\mathrm{m}} \mathrm{Q}_{\operatorname{lm}} \mathrm{Y}_{\mathrm{l}}^{\mathrm{m}}(\eta, \chi)
$$

After integration of $\mathrm{F}(\mathrm{g})$ (equation (1)), the new obtained expression is identified to equation (3) allowing to define a relation between the $Q_{1 m}$ and $f_{l m n}$ coefficients, so :

$$
\mathrm{Q}_{\mathrm{lm}}=2 \pi\left(\frac{2}{21+1}\right)^{1 / 2} \sum_{\mathrm{n}} \mathrm{f}_{\operatorname{lmn}} \mathrm{Y}_{1}^{\mathrm{n}^{*}}
$$

So, the $f_{\text {lmn }}$ coefficients corresponding to a set of experimental pole figures (the pole figure number defines the expansion order $L$ ) can be calculated. From the $f_{1 m n}$ coefficients, the ODF can be thus calculated (equation (1)). Moreover, the pole densities corresponding to experimental pole figures or not can also be recalculated (equations ( 4 and 3 )).

\subsubsection{Incomplete pole figures}

When the pole figures are measured by X-ray diffraction in reflection, the periphery of these pole figures cannot be determined because of the defocusing problem. Consequently, it becomes necessary to introduce a new mathematical approach which allows one to complete the pole figures. For that, an iterative method that takes into account the positivity condition of pole densities can be used (see $[9,10]$; the method described in reference [9] is used in this study).

\subsubsection{Overlapped pole figures $[9,11]$}

If the $\mathrm{j}$ index defines a phase, for the $\mathrm{i}$ overlapped pole figures of the $\mathrm{j}$ phases, one obtains :

$$
\left.q_{\theta}(\eta, \chi)=\sum_{j=1}^{J} \sum_{i=1}^{I} \alpha_{i j} q_{h_{i j}}(\eta, \chi) \quad \text { (with } \sum_{j=1}^{J} \sum_{i=1}^{I} \alpha_{i j}=1\right)
$$

Taking into account the relation between $q(\eta, \chi)$ and $Q_{\operatorname{lm}}$ (equation (3)), one obtains : 


$$
Q_{\operatorname{lm}}(\theta)=\sum_{j=1}^{J} \sum_{i=1}^{I} \alpha_{i j} Q_{\operatorname{lm}}\left(h_{i j}\right)
$$

Consequently, equation (4) becomes :

$$
Q_{\operatorname{lm}}(\theta)=2 \pi\left(\frac{2}{21+1}\right)^{1 / 2} \sum_{j=1}^{J} \sum_{n=0}^{N(1, j)} f_{l m n}(j) \sum_{i=1}^{I(j)} \alpha_{i j} Y_{1}^{n^{*}}\left(h_{i j}\right)
$$

Where the $\mathrm{f}_{\operatorname{lmn}}$ and the $\alpha_{\mathrm{ij}}$ are the unknowns. To simplify the resolution, at the initial state (iteration $\mathrm{N}^{\circ} 0$ ), the $\alpha_{\mathrm{ij}}$ values are assumed to be known (so for example, if two pole figures are overlapped then $\alpha_{1}=\alpha_{2}$ $=0,5)$. Thus, it is easy to solve equation (7) because it is the same that equation (4) where only the $f_{1 \mathrm{mn}}$ coefficients are unknown. From the $f_{\operatorname{lmn}}$ coefficients, the $\mathrm{Q}_{\mathrm{lm}}$ corresponding to the non overlapped pole figures can be recalculated and compared to the experimental overlapped ones. This comparison which uses a mean square method allows one to find new $\alpha_{\mathrm{ij}}$ values to continue the iterative calculation (equation (7)) until the convergency of the $\alpha_{i j}$ values is obtained.

\subsubsection{Total texture function}

The global texture analyses do not permit to separate the $+h_{i}$ et $-h_{i}$ directions of centrosymmetrical crystals [6]. In these conditions, it appears a mathematical indetermination since only the even part $\tilde{F}(\mathrm{~g})$ (l even) can be calculated from pole figures. To assess the odd part $\tilde{\tilde{F}}(\mathrm{~g})$ and so the total ODF, it becomes necessary to introduce a new iterative procedure that allows one to estimate $F(g)$ from $\tilde{F}(g)$ using the positivity condition of $\mathrm{F}(\mathrm{g})(\mathrm{F}(\mathrm{g})=\tilde{\mathrm{F}}(\mathrm{g})+\tilde{\tilde{\mathrm{F}}}(\mathrm{g}) \geq 0)$.

\subsubsection{Example}

To sum up, in the more defavourable case, to calculate the ODF, it is necessary to use the harmonic method plus 3 iterative methods to solve the problems of incomplete and overlapped pole figures and to calculate the total ODF. To illustrate this approach a theoretical two phases (tetragonal and hexagonal) material is defined. Each phase is characterized by one orientation that is modelled with a gaussian function (see section 2.2). This approach allows one to construct pole figures :

*Tetragonal phase : 7 pole figures $\left(y=22,67, \theta=56,14, \varphi=26,57\right.$ with $c / a=2,0, \phi_{0}=15^{\circ}$ and $\left.L=22\right)$

*Hexagonal phase : 6 pole figures $\left(\psi=\theta=\varphi=0,00\right.$ with $\mathrm{c} / \mathrm{a}=1,6, \phi_{0}=25^{\circ}$ and $\mathrm{L}=22$ ).

Then to assume $\mathrm{X}$-ray measurements, the periphery $\left(10^{\circ}\right)$ of pole figures is suppressed and finally, the $\{110\}$ and $\{10 \overline{1} 0\}$ pole figures are numerically overlapped. Table 1 allows one to compare the given values to those calculated with the so described approach and shows the quality of this method.

\begin{tabular}{|c|c|c|c|}
\cline { 3 - 4 } \multicolumn{2}{c|}{} & Tetragonal phase $\{110\}$ & Hexagonal phase $\{10 \overline{1} 0\}$ \\
\cline { 2 - 4 } & Given & 0,7000 & 0,3000 \\
\hline \multirow{2}{*}{ Maximal values of $\tilde{\mathrm{F}}(\mathrm{g})$} & Calculated & 0,6998 & 0,3002 \\
& Local analysis & 66,6 & 13,3 \\
\cline { 2 - 4 } & Global analysis & 66,7 & 13,2 \\
\hline Maximal values of $\mathrm{F}(\mathrm{g})$ & Local analysis & 97,4 & $\mathbf{1 4 , 6}$ \\
& Global analysis & 97,0 & 14,4 \\
\cline { 2 - 4 } &
\end{tabular}

Table 1: Comparison of theoretical and calculated values of $\alpha, \tilde{F}(g)$ and $F(g)$ 


\subsection{EBSD}

The $\mathrm{f}_{\mathrm{lmn}}$ coefficients can be calculated from individual orientations, each orientation being modelled with a gaussian function [12] :

$$
f_{\operatorname{lmn}}=\frac{1}{N} \sum_{i=1}^{N} K_{m n}^{l_{m}^{*}}\left(g_{i}\right)
$$

$\mathrm{K}$ defines the gaussian function where the $\phi_{0}$ parameter characterizes the width at half height of the gaussian. Obviously, the main difficulty of this approach consists to choose the right number of orientations to calculate a statistical ODF i.e. comparable to the ODF calculated from pole figures measured for example by X-ray diffraction $[13,14]$.

When this kind of local or global analysis is used, the microstructure is assumed to be homogeneous because only the 3 orientation parameters are taken into account. Only a local approach allows one to define the 6 (or 5 in the case of a two dimensional analysis) parameters allowing to weight each orientation by the grain area measured by image analysis or defined by an orientation number measured in the grain if the local measurements are performed on a defined grid. This last approach can be used when the EBSD is automatized (stage displacement and Kikuchi pattern indexation). This technique allowing to built up the studied microstructure is named Orientation Imaging Microscopy (OIM) [15]. The orientations are measured at each point of a $X Y$ grid $(\Delta X=\Delta Y>0,1 \mu \mathrm{m})$. Then knowing that if two consecutive points have the same orientation they are in the same grain and on the contrary if the orientations are different a grain boundary separates the two points, it becomes easy to built up the grey level microstructure as a function of the Kikuchi pattern quality (white for beautiful patterns and black for poor patterns) or the color microstructure, each grain being colored according to the crystallographic orientation [16].

\section{GLOBAL TEXTURE OF A TITANIUM ALLOY $(50 \% \alpha / 50 \% \beta)$}

The used titanium alloy was annealed to obtain a "school" sample with two cubic and hexagonal phases having approximatively the same volume fraction. The texture of the two phases is characterized by X-ray diffraction in reflection and by EBSD. In the first case, 7 incomplete pole figures $\left(10^{\circ}\right.$ at the periphery are not determined) have been measured knowing that the $\{110\}$ and $\{0002\}$ and the $\{211\}$ and $\{01 \overline{1} 3\}$ pole figures are overlapped. The $\mathrm{ODF}$ of each phase is calculated with $\mathrm{L}=34$. In the second case, a square surface has been studied $(X=Y=200 \mu \mathrm{m} ; \Delta X=\Delta Y=1 \mu \mathrm{m})$. Figures $1 \mathrm{a}$ and $1 \mathrm{~b}$ show respectively the experimental microstructure with $\alpha$ nodules in the $\beta$ matrix and the microstructure built up from orientation measurements. In this last case, it is interesting to note that the volume fraction of cubic (grey) and hexagonal (black) phases have been found equal to $46 \%$ and $54 \%$ so very closed to the imposed volume fraction according to the heat treatment. One can observe that the grain boundaries are not perfectly define because the exploration step was too large. Indeed, to improve the microstructure definition (that is not the aim here) it is necessary to decrease the grid step.

With the EBSD, it becomes easy to separate the two phases and so to calculate the corresponding ODFs. Figures $2 \mathrm{a}$ and $2 \mathrm{~b}$ show the $\varphi_{1}=90^{\circ}$ constant section plot of the ODF calculated for the cubic phase from pole figures measured by $X$-ray diffraction and from about 11200 individual orientations $\left(\phi_{0}=10^{\circ}, L=34\right)$ respectively.

The obtained results (main component near $\{130\}<001>$ ) are quite similar even if some differences appear firstly due to the sample location during the experiments and secondly to the choice of $\phi_{0}$ [14]. Moreover, it should be interesting to verify if the orientation number or more exactly the grain number is sufficient to calculate an ODF, knowing that it appears some microstructural heterogeneities on figure $1 \mathrm{~b}$. 


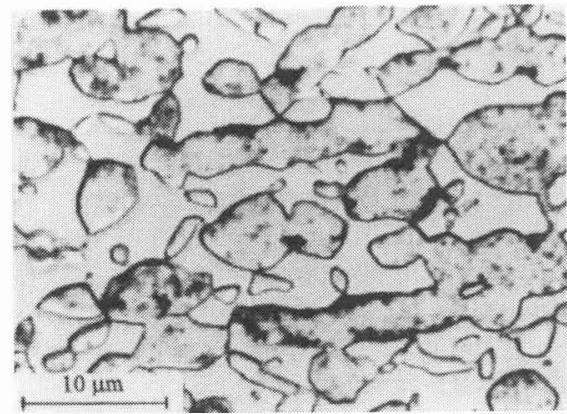

(a)

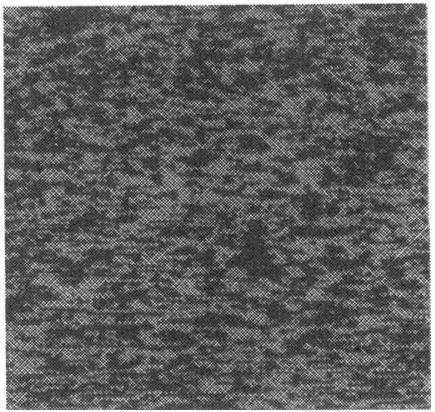

(b)

Figure 1: (a) experimental microstructure and (b) built up microstructure from EBSD

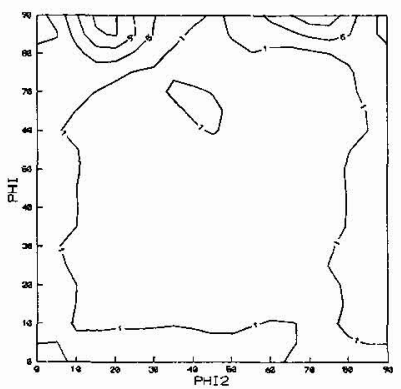

(a)

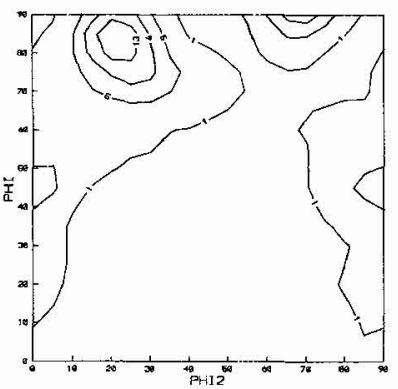

(b)

Figure 2: $\varphi_{1}=90^{\circ}$ constant section plot of the ODF calculated (a) from X-ray diffraction and (b) from EBSD

\section{LOCAL TEXTURE OF THE Ti48A148Cr2Nb2 ALLOY}

This material so called GE (General Electric) provided by ONERA is particularly studied by Dupont et al. [17]. Here, it is studied after a heat treatment $\left(1150^{\circ} \mathrm{C}-24\right.$ hours $)$. The texture measured on the tetragonal phase (the volume fraction of the hexagonal phase is too low (about $5 \%$ )) by neutron diffraction (because of the large grain size) shows a $\{111\}<u v w>$ fiber texture (the fiber axis is perpendicular to the ingot axis). Figure 3 a shows the microstructure $(X=Y=350 \mu \mathrm{m} ; \Delta X=\Delta Y=1 \mu \mathrm{m})$ built up from individual orientations and figure $3 \mathrm{~b}$ shows that the crystallographic planes of lamellae sets ( 1 and 2) and twinned monolithic grain (about $23 \%$ of the volume fraction of the sample) (3 and 4) are near $\{111\}$ (see [17]).

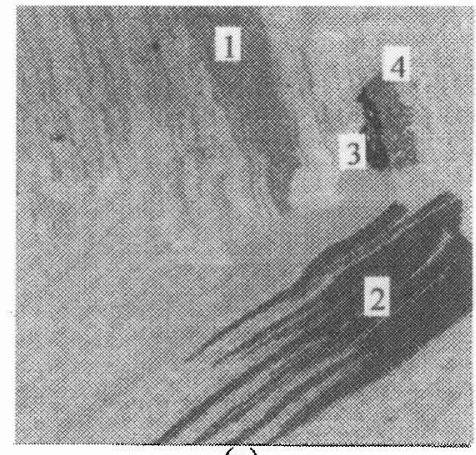

(a)

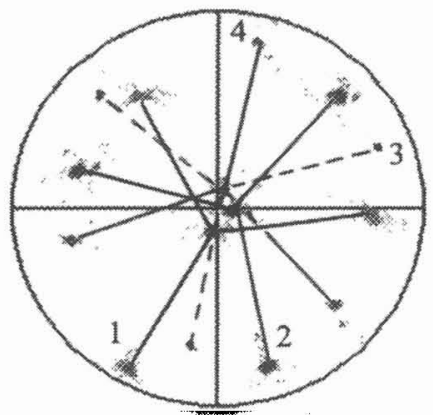

(b)

Figure 3: (a) built up microstructure and (b) $\{111\}$ pole figure corresponding to some parts of microstructure (a) 


\section{CONCLUSION}

The present study shows the advantages and the disadvantages of the global and local texture analyses in particular for intermetallic materials and in a general case for all multiphase materials. However, as it was described, all the disadvantages can be solved, and consequently it becomes difficult to choose the best method. In fact and in a general case, except for material with large or very large grains for which the Xray and neutron cannot be used respectively, the two approaches are complementary.

In the case of EBSD measurements, the most important problem concerns the choice of the sufficient orientation number to calculate the ODF and it depends on the experimental procedure. Indeed, in a first approach, the orientations can be randomly measured on the surface analysed by $\mathrm{X}$-ray diffraction and in a second approach, only a part of the microstructure can be analysed and in this last case, it is necessary to verify that the observed domain is representative of the total surface studied by X-ray diffraction.

\section{Acknowledgements}

Authors would like to thank S. Naka and M. Thomas from ONERA for fruitful discussions and for supplying the GE sample which was prepared by M.L. Dupont with LMS Orsay. TB and RP thank the DGA/DRET for its financial support that has permitted the development of a part of softwares.

\section{References}

[1] Yamaguchi $M$. and Inui $\mathrm{H}$., "TiAl compounds for structural applications", First International Symposium on Structural Intermetallics, Seven Springs Mountain Resort, Champion, Pennsylvania, September 26-30 1993, R. Dariola, J.J. Lewandowski, C.T. Liu, P.L. Martin, D.B. Miracle and M.V. Nathal Eds. (TMS, Warrendale, Pennsylvania, 1993) pp. 127-142

[2] Dingley D.J., "On line microtexture determination using backscatter Kikuchi diffraction in a scanning electron microscope", Eighth International Conference on Textures of Materials, Santa Fe, USA, September 20-25, 1988, J.S. Kallend and G. Gottstein Eds. (The Metallurgical Society, Warrendale, Pennsylvania, 1988).pp. 189-194.

[3] Dahms M., Beaven P.A., Tobisch J., Bermig G. and Helming K., Z. Metallkd. 85 (1994) 536-544.

[4] Wiglin A.S., Soviet Phys. Solid State 1 (1960) 229-233.

[5] Bunge H.J., Z. Metallkd. 56 (1965) 827-874.

[6] Bunge H.J., Texture Analysis in Materials Science (Butterworth, London, 1982).

[7] Roe R.J., J. Appl. Phys. 36 (1965) 2024-2031

[8] Roe R.J., J. Appl. Phys. 37 (1966) 2069-2072.

[9] Dahms M. and Bunge H.J., J. Appl. Cryst., 22 (1989) 439-447.

[10] Baudin T., Penelle R., Ceccaldi D. et Royer F., Mém. Sci. Rev. Mét. N¹0 (1990) 611-618.

[11] Dahms M., J. Appl. Cryst. 25 (1992) 258-267.

[12] Baudin T. and Penelle R., J. Appl. Cryst. 26 (1993) 207-213.

[13] Baudin T. and Penelle R., Met. Trans., 24A (1993) 2299-23 11.

[14] Baudin T., Jura J., Penelle R. and Pospiech J., J. Appl. Cryst (in press).

[15] Adams B.L., Wright S.I. and Kunze K., Met. Trans. A. 24A (1993) 819-831.

[16] Baudin T., Paillard P. et Penelle R., C. R. Acad. Sci., Paris, t. 319, Serie II (1994) 1307-1311.

[17] Dupont M.L., Baudin T., Penelle R., Naka S. and Thomas M., this symposium. 